DOI 10.37882/2223-2982.2021.08.02

\title{
ПОВЫШЕНИЕ ПРОФЕССИОНАЛЬНОЙ КОМПЕТЕНТНОСТИ СТУДЕНТОВ В ПРОЦЕССЕ ОСВОЕНИЯ ДИСЦИПЛИНЫ «ФИЗИЧЕСКАЯ КУЛЬТУРА И СПОРТ» В ВУЗЕ
}

\section{INCREASING THE PROFESSIONAL COMPETENCE OF STUDENTS IN THE PROCESS OF MASTERING THE DISCIPLINE "PHYSICAL CULTURE" AT THE UNIVERSITY}

\section{A. Bolotnikov}

Summary: The article discusses the increase in the professional competence of students in the process of mastering the discipline "physical culture" in the university. The urgency of the professional development of a future specialist by means of physical culture has been substantiated. The analysis of the capabilities of the competence-based approach in the development of the discipline "Physical culture" at the university. The groups of professional competencies of university students in the process of mastering the discipline "physical culture" have been determined. It is concluded that improving the professional competencies of students in the process of mastering the discipline "physical culture" at the university provides for the creation, based on the competencebased approach, of an integral concept of the student's personal and professional development at the personal, social and activity levels.

Keywords: professional competence, physical culture, educational and training process, healthy lifestyle.
$\mathrm{B}$ настоящее время физическая культура трактуется как важнейший компонент целостного личностного и профессионального развития будущего специалиста ввиду акцентирования внимания государством и обществом на ценностях здорового образа жизни, что формирует новые тенденции в развитии личностной мотивации занятий физической культурой и спортом каждым человеком. Требования мирового образовательного пространства предполагают наличие у будущего выпускника ВУЗа способности предпринимать конструктивные решения, быть стресс устойчивым, адаптируясь к постоянным изменениям, быть готовым пополнять свои знания и применять их из разных научных областей [6].

В системе общечеловеческих культурных ценностей одной из главных составляющих является уровень здоровья и физической подготовленности людей разных возрастных периодов [5].

Согласно Федеральному государственному образовательному стандарту высшего образования, выпускник ВУЗа должен обладать универсальной компетенцией

\author{
Болотников Анатолий Александрович \\ к.п.н., дочент, Университет управления «ТИСБИ» \\ (2. Казань) \\ tank.rt@mail.ru
}

Аннотация: В статье рассматривается повышение профессиональной компетентности студентов в процессе освоения дисциплины «Физическая культура и спорт» в ВУЗе. Обоснована актуальность профессионального развития будущего специалиста средствами физической культуры. Проведен анализ возможностей компетентностного подхода при освоении дисциплины «Физическая культура и спорт» в ВУЗе. Определены группы профессиональных компетенций студентов ВУЗа в процессе освоения дисциплины «Физическая культура и спорт». Сделан вывод 0 том, что повышение профессиональных компетенций студентов в процессе освоения дисциплины «Физическая культура и спорт» в ВУЗе предусматривает создание на основе компетентностного подхода целостной концепции личностного и профессионального развития студента на личностном, социальном и деятельностном уровнях.

Ключевые слова: профессиональная компетентность, физическая культура, учебно-тренировочный процесс, здоровый образ жизни.

для поддержания на должном уровне физической подготовленности для обеспечения полноценной социальной и профессиональной деятельности. Если ранее сфера освоения данной дисциплины ограничивалась овладением знаний, навыков выполнения физических упражнений, то с внедрением новых стандартов высшего образования на первое место выдвинулся компетентностный подход, направленный на формирование общекультурных, общепрофессиональных и профессиональных компетенций [1].

По мнению О.А. Мельниковой, И.Н. Шевелевой, одним из средств социального и личностного становления будущего выпускника ВУЗа выступает физическая культура. Авторы отмечают следующие возможности данной дисциплины: формирование патриотизма, командного взаимодействия, взаимопомощи, индивидуально и профессионально значимых личностных качеств [4].

Анализ программ по дисциплине «Физическая культура и спорт» позволяет говорить о том, что существуют противоречия между требованиями существующих 
программ и социальными ожиданиями в сфере высшего профессионального образования, ориентированными на формирование готовности к профессиональной деятельности и личностное развитие [6].

И.В. Иванцова [3], Е.И. Смирнова [7] указывают, что анализ целевых компонентов дисциплины программ ВУЗов позволяет определить основную ее направленность: формирование гражданской позиции, успешная социализация в обществе, реализация потенциала физической культуры для обеспечения становления личности будущего специалиста.

Изучение возможностей компетентностного подхода при освоении дисциплины «Физическая культура» позволяет говорить о том, что она обладает достаточно большим потенциалом для развития как общекультурных, так и профессиональных компетенций студентов ВУЗа, поскольку к особенностям использования компетентностного подхода при освоении дисциплин в ВУЗе следует отнести задачу научить выпускника адаптироваться к происходящим в обществе и мире изменениям, формировать способность самостоятельно принимать решения и нести ответственность за них, находить оптимальные пути решения сложившейся ситуации. В связи с этим повышение профессиональных компетенций в процессе освоения дисциплины «Физическая культура» приобретает особую значимость посредством создания оптимальных условий для их развития средствами из-

\section{бранного вида спорта.}

\section{Шель и методы исследования}

Целью исследования является разработать модель повышения профессиональной компетентности студентов в процессе освоения дисциплины «Физическая культура и спорт» в ВУЗе.

Методами исследования послужили анализ научнометодической литературы по проблеме исследования, синтез и обобщение информации.

\section{Результаты исследования}

Проведенный анализ теоретических положений по вопросам понимания профессиональных компетенций позволил определить следующие группы профессиональных компетенций студентов ВУЗа в процессе освоения дисциплины «Физическая культура и спорт»:

1. Личностные компетенции, направленные на:

- поддержание здорового образа жизни (способность организовать и поддерживать здоровый образ жизни для обеспечения собственной социальной активности и личностной безопасности);

- интеграцию (способность самостоятельно применять методы и средства для получения новых знаний и поддержания здорового образа жиз-

Таблица 1.

Методы повышения профессиональных компетенций студентов в процессе освоения дисциплины «Физическая культура и спорт» в ВУЗе

\begin{tabular}{|c|c|c|}
\hline Группа компетенций & Направленность компетенций & Методы \\
\hline \multirow[t]{5}{*}{1} & Поддержание здорового образа жизни & $\begin{array}{l}\text { Самостоятельная физическая подготовка } \\
\text { Учебно-тренировочные занятия }\end{array}$ \\
\hline & Интеграция & $\begin{array}{l}\text { Самостоятельная физическая подготовка } \\
\text { Учебно-тренировочные занятия }\end{array}$ \\
\hline & Самосовершенствование & $\begin{array}{l}\text { Самостоятельная физическая подготовка } \\
\text { Участие в спортивных мероприятиях / соревнованиях }\end{array}$ \\
\hline & Гражданственность & $\begin{array}{l}\text { Патриотическое воспитание } \\
\text { Учебно-тренировочные занятия } \\
\text { Участие в спортивных мероприятиях / соревнованиях }\end{array}$ \\
\hline & Ценностно-смысловые ориентации & Участие в спортивных мероприятиях / соревнованиях \\
\hline 2 & Социальное взаимодействие & $\begin{array}{l}\text { Командные виды спорта } \\
\text { Спортивные игры } \\
\text { Участие в спортивных мероприятиях / соревнованиях }\end{array}$ \\
\hline \multirow[t]{3}{*}{3} & Познание & $\begin{array}{l}\text { Учебно-тренировочные занятия } \\
\text { Самостоятельная физическая подготовка }\end{array}$ \\
\hline & Деятельность & $\begin{array}{l}\text { Участие в спортивных мероприятиях } \\
\text { Самостоятельная физическая подготовка }\end{array}$ \\
\hline & Применение информационных технологий & $\begin{array}{l}\text { Самостоятельная физическая подготовка } \\
\text { Спортивная подготовка }\end{array}$ \\
\hline
\end{tabular}


ни);

- самосовершенствование (способность и готовность повышать свою самостоятельность, интеллектуальный, общекультурный уровень развития);

- гражданственность (действия в соответствии с гражданской позицией о здоровом образе жизни);

- ценностно-смысловых ориентаций (готовность следовать принципам здорового образа жизни).

2. Компетенции, направленные на социальное взаимодействие (способность и готовность принимать решения по отношению к другим людям и самому себе в целях сохранения и поддержания здорового образа жизни).

3. Компетенции, направленные на:

- познание (способность критически оценивать свои зоны роста и самостоятельно определять пути для самосовершенствования);

- деятельность (самостоятельное применение методов физического воспитания для укрепления здоровья для обеспечения полноценной социальной и профессиональной деятельности);

- применение информационных технологий (применение разных методов поиска, переработки и хранения информации).

Представим методы повышения профессиональных компетенций студентов в процессе освоения дисциплины «Физическая культура и спорт» в ВУЗе
Исходя из таблицы 1, развитие личностных компетенций осуществляется посредством учебно-тренировочных занятий, самостоятельной физической подготовки, участие в спортивных мероприятиях / соревнованиях.

Формирование компетенций, направленных на социальное взаимодействие, реализуется в процессе командных видов спорта, участия в соревнованиях. Командная и игровая направленность упражнений / занятий обеспечивает развитие способности правильно оценивать ситуацию, находить способы ее решения, в команде принимать решения и нести за них ответственность.

Развитие и повышение деятельностных компетенций осуществляется посредством самостоятельной физической и спортивной подготовки, что предусматривает повышение уровня сформированности способностей выбирать пути самосовершенствования, достигать цели.

Таким образом, структуризация выбранных методов обеспечивает повышение профессиональных компетенций студентов в процессе освоения дисциплины «Физическая культура и спорт» в ВУЗе

\section{Зак^ючение}

Таким образом, повышение профессиональных компетенций студентов в процессе освоения дисциплины «Физическая культура и спорт» в ВУЗе предусматривает создание на основе компетентностного подхода целостной концепции личностного и профессионального развития студента на личностном, социальном и деятельностном уровнях.

\section{ЛИТЕРАТУРА}

1. Адольф В.А. К вопросу о реализации новых образовательных стандартов / В.А. Адольф, Н.В. Пилипчевская // Мир образования - образование в мире. № 3. - 2012. - С. 18-23.

2. Бойцова Т.Л. Реализация личностно-ориентированного подхода в физкультурном образовании студентов / Т.Л. Бойцова // Образовательная и оздоровительная роль физической культуры и спорта в вузе: материалы III Международ. науч.-практ.конф., посвящ. 50-летию образования, 27-28 янв.-М.: РУДН., 2010. - С. 3-7.

3. Иванцова И.В. Формирование у студентов вуза компетенции, направленной на овладение методами правильного использования физического воспитания и укрепления здоровья / И.В. Иванцова // Региональная науч.-практ. интернет конф. «Философия образовательного учреждения в условиях реализации ФГОС нового поколения» УНПК, Ливны. - 2012. - С. 16.

4. Мельникова 0.А. Компетентностный подход в физическом воспитании студентов вуза / 0.А. Мельникова, И.Н. Шевелева // Омский научный вестник. 2013. - № 5 (122). - С. 189-191.

5. Нигматзянова Г.Х. Структура и содержание общекультурных компетенций студента / Г.Х. Нигматзянова // Гуманитарные научные исследования. - 2014. № 2. - URL: http://human.snauka.ru/2014/02/5851 (дата обращения: 31.05.2021).

6. Овсянникова Е.К. Особенности формирования общекультурных компетенций студентов медицинского вуза / Е.К. Овсянникова // Международный журнал экспериментального образования. - 2012. - № 4. - С. 177-180

7. Смирнова Е. И. Реализация компетентностного подхода при освоении дисциплины «Физическая культура» в педагогическом вузе / Е.И. Смирнова // Образование в XXI веке: материалы Всеросс. науч. заоч. конф. - Тверь: Изд-во «Купол». - 2010. - С. 141-143.

(с) Болотников Анатолий Александрович (tank.rt@mail.ru).

Журнал «Современная наука: актуальные проблемы теории и практики» 